anales de psicología / annals of psychology

2019, vol. 35, nº 2 (may), 280-289

http://dx.doi.org/10.6018/analesps.35.2.331441
(C) Copyright 2019: Editum. Servicio de Publicaciones de la Universidad de Murcia. Murcia (Spain) ISSN print edition: 0212-9728. ISSN on line edition (http://revistas.um.es/analesps): 1695-2294.

On line edition License Creative Commons 4.0: BY-NC-ND

\title{
Clarifying the two facets of Self-Oriented Perfectionism: influences on affect and the Big Five traits of personality in children
}

\author{
María Vicent ${ }^{1, *}$, Cándido J. Inglés ${ }^{2}$, Ricardo Sanmartín ${ }^{1}$, Carolina Gonzálvez ${ }^{1}$, María P. Aparicio-Flores ${ }^{1}$, \\ and José M. García-Fernández ${ }^{1}$ \\ 1 University of Alicante (Spain). \\ 2 Miguel Hernández University of Elche (Spain).
}

\begin{abstract}
Título: Aclarando las dos facetas del perfeccionismo auto-orientado: las influencias sobre el afecto y los rasgos de la personalidad del Big Five en niños.

Resumen: Este estudio analiza la relación entre las dimensiones del perfeccionismo, es decir, el perfeccionismo auto-orientado-críticas (SOP-C) y el perfeccionismo auto-orientado-esfuerzo (SOP-S), y el afecto y los rasgos de personalidad del Big Five en una muestra de 804 españoles entre 8 y 11 años $(M=9.57 ; D T=1.12)$. Se utilizaron la prueba $t$ de Student, el índice $d$ de Cohen y el análisis de regresión logística. El grupo con alto SOP-C obtuvo una puntuación significativamente mayor que la de sus compañeros con bajo SOP-C en Afecto Negativo y Neuroticismo, así como significativamente menor en Afecto Positivo, Amabilidad, Conciencia y Apertura a la Experiencia. Por el contrario, los estudiantes con alto SOP-S obtuvieron puntuaciones significativamente más altas en todas las dimensiones adaptativas (es decir, Afecto Positivo, Extraversión, Amabilidad, Conciencia y Apertura a la Experiencia), y más bajas en Afecto Negativo y Neuroticismo. Los tamaños del efecto fueron pequeños para la mayoría de las diferencias estadísticamente significativas. Estos hallazgos también fueron apoyados por el análisis de regresión. Los resultados se discuten a la luz del debate sobre la naturaleza adaptativa o desadaptativa del perfeccionismo auto-orientado.

Palabras clave: perfeccionismo auto-orientado-críticas; perfeccionismo
\end{abstract} auto-orientado-esfuerzo; afecto; Big Five; niños.

\section{Introduction}

Research on perfectionism has been growing exponentially over last decades. However, far from having clarified this topic, the study of this personality trait remains quite relevant since numerous questions continue to lack expert consensus. Such is the case with the discussion regarding the factorial structure of perfectionism and on the adaptive or maladaptive nature of its dimensions.

Likewise, another interesting issue relates to the population used, mainly undergraduates from North America or northern European countries. Thus, the purpose of this work is to clarify the nature of Self-Oriented Perfectionism (SOP), which is considered the intrapersonal dimension of the multidimensional perfectionism model posed by Hewitt's research group (Hewitt, Flett, Besser, Sherry, \& McGee, 2003). This dimension has been defined as "the imposition on oneself of high goals that are unrealistic and impossible to achieve, as well as the tendency to harshly self-criticize when a mistake is made or when the proposed standards are not

* Correspondence address [Dirección para correspondencia]:

María Vicent, Department of Developmental Psychology and Teaching. University of Alicante, Carretera San Vicente del Raspeig s/n, 03690 San Vicente del Raspeig, Alicante (Spain). E-mail: maria.vicent@ua.es (Article received: 30-05-2018; revised: 09-07-2018; accepted: 06-11-2018)
Abstract: This study analyses the relationship between the perfectionism dimensions, i.e. Self-Oriented Perfectionism-Critical (SOP-C) and SelfOriented Perfectionism-Striving (SOP-S), and affect and the Big Five traits of personality in a sample of 804 Spanish students aged 8 to $11(M=9.57$; $S D=1.12$ ). Student's $t$ test, Cohen's $d$ index and logistic regression analysis were used. The high SOP-C group scored significantly higher than their peers having low SOP-C on Negative Affect and Neuroticism, and lower on Positive Affect, Agreeableness, Consciousness and Openness to Experience. To the contrary, students with high SOP-S scored significantly higher on all adaptive dimensions (i.e. Positive Affect, Extraversion, Agreeableness, Consciousness and Openness to Experience), and lower on Negative Affect and Neuroticism. Effect sizes were small for most of statistically significant differences. These findings were also supported by regression analysis. Results are discussed in light of the debate on the adaptive or maladaptive nature of Self-Oriented Perfectionism.

Keywords: Self-oriented perfectionism-criticism; self-oriented perfectionism-striving; affect; Big Five; children. achieved" (Vicent, Inglés, Sanmartín, Gonzálvez, \& GarcíaFernández, 2017, p. 106). Specifically, our study analyzes the relationship between Positive Affect (PA) and Negative Affect (NA) with this perfectionistic facet, as well as its association with the Big Five personality traits.

\section{Self-Oriented Perfectionism and affect}

The link between SOP and affect has been thoroughly researched. Frost, Heimberg, Holt, Mattia and Nuebauer (1993) developed one of the initial works in this sense, considering a sample of 533 U.S. undergraduates and concluding that SOP is positively associated with PA and nonsignificantly with NA. Later, Molnar, Reker, Culp, Sadava and DeCourville (2006) found similar results in a study on perfectionism and physical health in a North-American sample of 492 adults aged 24 to 35. Moreover, using structural equation analysis, the authors confirmed a model in which the relationship between SOP and physical health was completely mediated by affect. Concretely, SOP was linked with higher levels of PA and lower levels of NA, which in turn was associated with better physical health.

On the other hand, Dunkley, Zuroff and Blankstein (2006), using a sample of 163 North-American undergraduates $(M=20.02, S D=2.28)$ with retrospective and day-today measures, found that SOP only positively and signifi- 
cantly correlated with NA in the retrospective data. Similarly, using an American sample of 307 female university students aged 18 to 38, Downey and Chang (2007) found that NA positively and significantly correlated with SOP. Likewise, considering 92 female university students from Canada $(M=$ 22.20, SD = 6), Flett, Blankstein and Hewitt (2009) found that SOP was significantly and positively associated with PA, but not with NA.

Nejad, Ali-Besharat, Haddadi and Abdolmanafi (2011), in an Iranian sample of 234 adults aged 24 to 49, observed that SOP was significantly and positively linked with PA and negatively associated with NA. On the other hand, using a Canadian sample of 208 athletes aged 14 to 18, Gaudreau and Verner-Filion (2012) tested the 2 × 2 model of dispositional perfectionism with the perfectionism dimensions (i.e., Socially Prescribed Perfectionism and SOP). The authors found that the Pure SOP subtype did not obtain significantly higher levels of PA than Non-perfectionism and Mixed subtype. Short and Mazmanian (2013), using a Canadian sample of 213 undergraduates aged 18 to 28, found that SOP was not significantly linked with any of the affective dimensions. Subsequently, Downey, Reinking, Gibson, Cloud and Chang (2014), considering a sample of 480 U.S. university students aged 17 to 61, obtained positively and significantly correlations between SOP and PA, in males as well as females. These authors also observed that in no cases were the relationships between SOP and NA statistically significant.

Recently, Ho, Appleton, Cumming and Duda (2015) compared the scores between 212 English athletes with hearing disability $(M=27.30 ; S D=9.30)$ and 212 non-disabled people $(M=18.80 ; S D=3.90)$. The authors observed that SOP was significantly linked with NA in both samples. However, the relationship was in a positive sense in the case of disabled athletes and negative in the case of the nondisabled.

Finally, Stoeber and Corr (2015, 2016), considering 388 English university students $(M=19.80 ; S D=4.00)$, found that SOP significantly and positively correlated with NA and PA.

\section{Self-Oriented Perfectionism and the Big-Five per- sonality traits}

Hill, McIntire and Bacharach (1997) presented the first data on the relationship between SOP and the Big Five model, using a sample of 214 U.S. university students ( $M=$ 19). These authors found that SOP was only significantly and positively associated with Consciousness. Moreover, predictive analysis showed that Neuroticism and Consciousness positively predicted SOP, explaining $8 \%$ and $46 \%$ of variance, respectively. Conversely, Agreeableness negatively and significantly predicted SOP. Similarly, Nathanson, Paulhus and Williams (2006), using a Canadian sample of 350 university students $(M=19.13, S D=1.86)$, as well as Dunkley and Kyparissis (2008), who recruited a sample of 233 English and
French speaking adults, found only positive and significant correlations between SOP and Consciousness.

In this line, Cuttler and Graf (2007), in a study of 141 Canadian adults aged 18 to 81 years, demonstrated that SOP correlated positively and significantly with Consciousness, Agreeableness and Neuroticism. Using longitudinal data from a German sample of 214 adolescents aged 14 to 19 , Stoeber, Otto and Dalbert (2009) found that SOP negatively and significantly correlated with Agreeableness and Extraversion in time 1 . Likewise, the large positive correlations found between SOP and Consciousness in both time 1 and time 2 (after five months) are noteworthy. On the other hand, regression analysis evidenced that only Consciousness predicted longitudinal chances in SOP, but not the reverse. This result was later corroborated using cross-lagged analyses.

Recently, De Cuyper, Claes, Hermans, Pieters and Smits (2015) found that SOP negatively and significantly predicted Neuroticism and Extraversion, as well as Consciousness and Openness to Experience in a positive sense, when considering a Belgian sample of 959 undergraduates $(M=18.45$; SD $=1.75$.

Similarly, it is worth noting that other authors have provided data on the relationship between SOP and some of the Big Five personality traits without jointly considering all of them, especially Neuroticism (e.g., Brannan \& Petrie, 2008; Enns, Cox, \& Clara, 2005; Miquelon, Vallerand, Grouzed, \& Cardinal, 2005; Sherry \& Hall, 2009). Results of correlational analyses have revealed a positive and statistically significant association, with all of these studies having been carried out on North American adult and/or undergraduate student populations.

Moreover, Molnar, Flett, Sadava and Colautti (2012), considering a Canadian sample of 489 females with fibromyalgia $(M=48.78 ; S D=10.41)$, and Molnar, Sadava, Flett and Colautti (2012), looking at 550 Canadian university students $(M=22.38$; $S D=.81)$, only analyzed the traits of Consciousness, Extraversion and Neuroticism. Both studies found positive and significant correlations between SOP and Consciousness and Neuroticism, as well as significantly negative correlations with Extraversion in the study by Molnar, Flett et al. (2012). On the other hand, O'Connor and O'Connor (2004) found that SOP positively and significantly correlated with Consciousness in 155 university female students from the United Kingdom (aged 19 to 48). Along the same lines, Sherry, Hewitt, Sherry, Flett and Graham (2010), using a sample of 1258 North American Psychology professors $(M=48.06, S D=11.27)$, obtained positive and significant correlations between SOP and Consciousness and Neuroticism. In addition, authors contrasted the discriminant validity of SOP with respect to Consciousness, supporting the idea that they are distinct constructs. More recently, Walton, Hibbard, Coughlin and Coyl-Shepherd (2018), with a sample of 242 undergraduate college students in the US and the Middle East, found positive and significant correlations be- 
tween Openness, Consciousness and SOP, whereas these correlations were negative in the case of Neuroticism.

\section{Self-Oriented Perfectionism-Striving and Self- Oriented Perfectionism-Critical}

Over recent years, an intense debate has arisen over the adaptive or maladaptive nature of SOP, given that it often presents an ambiguous pattern of correlations (e.g., Flett \& Hewitt, 2006; Lo \& Abbott, 2013; Owens \& Slade, 2008). This has led to the questioning of SOP's consideration as a unitary construct.

In fact, for child and adolescent populations, various psychometric studies exist on The Child/Adolescent Perfectionism Scale (CAPS; Flett et al., 2016) that evidence a better data fit when self-criticism (SOP-C) and perfectionistic striving (SOP-S) facets are considered as independent dimensions. These studies also suggest that both dimensions represent the maladaptive and adaptive aspects of perfectionist introspection (McCreary, Joiner, Schmidt, \& Ialongo, 2004; O'Connor, Dixon, \& Rasmussen, 2009). Thus, McCreary et al. (2004), using an Afro-American sample of $6^{\text {th }}$ grade students $(M=11.80)$ observed positive and statistically significant correlations between SOP-S, depression and anxiety, as well as a non-significant correlation with conduct disorder. However, SOP-S did not significantly correlate with any of these three measures of psychological distress. Similarly, O'Connor, Rasmussen and Hawton (2010) considered 737 Scottish adolescents $(M=15.2 ; S D=.7)$ and found that SOP-C positively and significantly correlated with anxiety, depression and stress, whereas SOP-S was negatively and significantly linked to stress and non-significantly linked to anxiety and depression. Subsequently, Herman, Wang, Trotter, Reinke and Ialongo (2013) analyzed the trajectory of the SOP-C using longitudinal data in an Afro-American sample of 547 students in $2^{\text {nd }}$ to $6^{\text {th }}$ grade. The authors concluded that those students with high SOP-C scores had a higher risk of developing a depressive or anxious disorder during adolescence. Recently, Harvey, Moore and Koestner (2017), using a Canadian sample of 203 children aged 8 to 12, found that SOP-S positively correlated with academic performance. Nevertheless, this dimension did not significantly correlate with NA or PA. Contrarily, SOP-C significantly and positively correlated with only NA.

\section{This study}

The review of the scientific literature with regard to SOP, affect and the Big Five traits of personality has revealed the following shortcomings. Firstly, because studies have primarily been conducted with adult or undergraduate student populations, no previous research exists on this issue with regards to children under the age of 12 . However, several authors have defended the importance of carrying out research on perfectionism during childhood (e.g., Morris \& Lomax, 2014), not only in order to understand its origins and devel- opment trajectories, but also because clinical and educational experience have recurrently shown cases of perfectionist children at early ages (Oros, 2005).

As a second limitation, most of studies analyzed have considered English-speaking populations, specifically North Americans. Thus, no prior work has considered Spanish or Spanish-Speaking populations, despite the fact that several authors have defended the importance of extending research on the correlates of perfectionism to other ethnic groups (Burgess, DiBartolo, \& Rendón, 2016). This is due to the existence of certain cultural factors that may influence how perfectionism is manifested and its consequences on psychological wellbeing (DiBartolo \& Rendón, 2012).

Thirdly, except for the results on Consciousness, previous literature offers contrary conclusions with respect to the link between SOP and affect dimensions and the Big Five personality traits. This situation may be because the mentioned studies did not separately consider the self-criticism and striving facets of SOP. Moreover, there is very limited prior literature examining correlates of SOP-C and SOP-S. Consequently, their adaptive/maladaptive nature is not yet clear.

In order to overcome these limitations, this study aims to examine the relationship between perfectionism dimensions (i.e., SOP-C and SOP-S), affect and the Big Five personality traits in Spanish child population. Specifically, this study has two goals: (a) to analyze whether there are statistically significant differences between students with high and low levels of SOP-C and SOP-S in the mean scores on PA, NA and the Big Five personality traits; (b) and to examine the predictive capability of PA, NA and the Big Five traits on high scores in SOP-C and SOP-S. Based on the results of previous research examining the correlates of SOP-C and SOP-S (Harvey et al., 2017; Herman et al., 2013; McCreary et al., 2004; O'Connor et al., 2010) which suggests that both dimensions are of a maladaptive and adaptive nature, respectively, it is expected that: (a) students with high SOP-C will score significantly higher on NA and Neuroticism and significantly lower on PA, Extraversion, Consciousness and Openness to Experience than their peers having low levels of SOP-C; (b) participants with high SOP-S will score significantly lower on NA and Neuroticism and higher on PA, Extraversion, Consciousness and Openness to Experience than their peers having low levels of SOP-S. Similarly, (c) NA and Neuroticism are expected to be positive and negative predictors of high SOP-C and SOP-S, respectively, whereas (d) PA, Extraversion, Consciousness and Openness to Experience are expected to negatively and positively predict high levels of SOP-C and SOP-S, respectively.

\section{Material and methods}

\section{Participants}

An initial sample of 982 students was selected using multi-stage random cluster sampling in the following geographic 
areas: central, north, south, east and west of the Alicante, Murcia and Albacete provinces (Spain). A total of 10 schools and one group per primary school grade $\left(3^{\text {rd }}\right.$ to $\left.6^{\text {th }}\right)$ were selected. From the initial sample, $13.17 \%$ of the participants were excluded due to errors and/or omissions in their responses, because they were repeating students or because they did not have the minimum reading level, as well as $4.96 \%$ because their parents did not provide written consent to participate in this study. Thus, the final sample consisted of 804 students aged 8 to $11(M=9.57, S D=1.12)$ with $48.3 \%$ being female. Participants aged 8, 9, 10 and 11 respectively represented $21.9 \%, 27.1 \%, 22.6 \%$ and $28.4 \%$ of the sample, confirming homogeneity of the frequency distribution regarding sex and age $\left(\chi^{2}=5.08, p=.17\right)$. The ethnic composition of the sample was: $86.94 \%$ Spaniards, $6.34 \%$ African, 4.73\% Latin-American, 1.37\% from other European countries different to Spain, and $.87 \%$ Asian.

\section{Instruments}

SOP-C and SOP-S subscales of the Spanish version of the Child/Adolescent Perfectionism Scale (CAPS; Flett et al., 2016; Vicent, 2017), were employed. The CAPS is currently the most frequently used instrument to assess perfectionism during youth and childhood (García-Fernández et al., 2016). Both SOP-C (e.g., "I get angry with myself when I make a mistake") and SOP-S (e.g., "I try to be perfect in everything I do") have four items rated on a five-point Likert scale, and assess, respectively, perfectionist self-criticism, the fear to make mistakes and the desires and the effort to achieve perfection.

The 10-Item Positive and Negative Affect Schedule for Children (10-item PANAS-C; Ebesutani et al., 2012) assesses PA (joyful, lively, happy, energetic and proud) and NA (depressed, angry, fearful/scared, afraid and sad) in children aged 6 to 18, using a Likert-type scale of five points. The original English version of the scale revealed adequate internal consistency indices for PA $(\alpha=.86)$ and for NA $(\alpha=.82)$. The scale was translated to the Spanish language using the backtranslation method, following the Hambleton and Lee (2015) recommendations.

The Big Five Questionnaire for Children (BFQ-C; Barbaranelli, Caprara, Rabasca, \& Pastorelli, 2003; Carrasco, Holgado, \& Del Barrio, 2005) assesses the Big Five personality traits during late childhood: Extraversion (refers to aspects such as activity, enthusiasm, creativity, assertiveness and selfconfidence; e.g., "I like to speak with other people"); Agreeableness (reflects the concern and sensitivity towards others and their needs; e.g., "I behave kindly with others"); Consciousness (assesses the dependability, orderliness, precision, and the fulfilling of commitments; e.g., "I respect the rules and order"); Neuroticism (examines feelings of anxiety, depression, discontent and anger; e.g., "I get angry with ease"); and Openness to Experience (reflects intellect, especially in the school domain; e.g., "When the teacher explains something, I understand it immediately"). It consists of 65 items and uses a five-point Likert scale. The Spanish validation of the scale revealed acceptable levels of reliability $(\alpha=$ between .88 and .78, respectively, for Consciousness and Neuroticism) (Carrasco et al., 2005).

In this study, acceptable levels of internal consistency, Cronbach's alpha, were obtained for all subscales of the CAPS, PANAS-C and BFQ-C (see Table 1).

Table 1. Reliability and descriptive data for perfectionism, affect and personality subscales.

\begin{tabular}{llccc}
\hline Scale & Variable & $M$ & $S D$ & $\alpha$ \\
\hline CAPS & SOP-C & 10.94 & 4.22 & .70 \\
& SOP-S & 15.70 & 3.32 & .72 \\
PANAS-C & PA & 19.62 & 4.07 & .75 \\
& NA & 8.58 & 3.77 & .76 \\
& Extraversion & 43.88 & 9.60 & .80 \\
& Agreeableness & 46.12 & 12.65 & .94 \\
BFQ-C & Consciousness & 45.59 & 11.87 & .90 \\
& Neuroticism & 34.97 & 10.81 & .85 \\
& Openness to Experience & 44.45 & 10.43 & .86 \\
\hline
\end{tabular}

\section{Procedure}

A meeting was held with the management team of the selected schools in order to request their collaboration. Subsequently, the written informed parental consent was requested from all participants. Once said consent was received, tests were administrated in a single 45-minute session, in groups and during school hours. A duly trained research team member was always present, highlighting the anonymous and voluntary nature of the activity.

\section{Data analysis}

First, the SOP-C and SOP-S dimensions were dichotomized in high (scores $\geq 75$ percentile) and low (scores $\leq 25$ percentile) levels. Student's t-test and Cohen's $d$ index were used to compare the scores on affect and personality between clusters with high and low levels in SOP-C and SOPS. To interpret $d$ index, the criteria proposed by Cohen (1988) was used, considering small (.20 - .49), moderate (.50 $.79)$ and large effect sizes $(\leq .80)$. In addition, binary logistic regressions, following the forward stepwise process based on Wald's statistic, were used to examine the predictive capacity of affect and personality on high scores for each of the perfectionism dimensions. This predictive capacity is estimated by an $O d d$ Ratio (OR) statistic, with levels above 1 indicating a positive prediction; below 1 , a negative prediction; and equal to 1, a lack of prediction (De Maris, 2003).

\section{Results}

\section{Mean differences}

Table 2 shows the results for the differences between high and low SOP-C in the mean scores of affect and personality. Statistically significant differences between both 
groups in NA and Neuroticism were found for the high SOP-C group, whose mean scores were higher. Moreover, the group with high SOP-C scored significantly lower on Agreeableness, Consciousness and Openness to Experience.
Effect sizes were small for all cases, with the exception of Openness to Experience, whose magnitude of differences were non-significant.

Table 2. Means, standard deviations and effect sizes for affect and the Big Five traits of personality obtained by groups with high and low SOP-C.

\begin{tabular}{|c|c|c|c|c|c|c|c|c|c|c|}
\hline & \multicolumn{2}{|c|}{ Levene's test } & \multicolumn{2}{|c|}{$\begin{array}{l}\text { High SOP-C group } \\
\quad N=239\end{array}$} & \multicolumn{2}{|c|}{$\begin{array}{l}\text { Low SOP-C group } \\
\quad N=208\end{array}$} & \multicolumn{4}{|c|}{ Statistical sig. and magnitude of differences } \\
\hline & F & $p$ & $M$ & $S D$ & $M$ & $S D$ & $t$ & $g l$ & $p$ & $d$ \\
\hline PA & 6.49 & .011 & 19.17 & 4.31 & 19.47 & 3.73 & .99 & 342.55 & .322 & - \\
\hline NA & 10.04 & .002 & 9.34 & 4.07 & 7.84 & 3.46 & -5.34 & 337.42 & $<.001$ & .39 \\
\hline Extraversion & 6.20 & .013 & 44.70 & 10.18 & 45.56 & 8.69 & -.89 & 412.13 & .191 & - \\
\hline Agreeableness & 18.75 & .000 & 46.37 & 12.92 & 49.17 & 10.82 & -3.30 & 413.33 & $<.001$ & .23 \\
\hline Consciousness & 20.77 & .000 & 46.22 & 12.20 & 49.10 & 10.13 & -2.85 & 417.58 & $<.001$ & .25 \\
\hline Neuroticism & 10.50 & .001 & 35.72 & 9.56 & 32.02 & 11.59 & -1.75 & 410.32 & $<.001$ & .35 \\
\hline Openness & 8.08 & .005 & 45.09 & 10.82 & 47.00 & 9.84 & -4.70 & 418.54 & .008 & .18 \\
\hline
\end{tabular}

Note: Openness = Openness to Experience

As for the results for differences in the values of affect and personality between groups with high and low SOP-S (see Table 3), the results revealed that participants with high SOP-S scored significantly higher on PA and in all traits of personality, except on Neuroticism, than their peers with low
SOP-S. On the contrary, the group with high SOP-S had significantly lower levels of NA and Neuroticism than the group with low SOP-S. The magnitude of differences was small in all cases, except for NA, whose effect sizes were non-significant.

Table 3. Means, standard deviations and effect sizes for affect and the Big Five traits of personality obtained by groups with high and low SOP-S.

\begin{tabular}{|c|c|c|c|c|c|c|c|c|c|c|}
\hline & \multicolumn{2}{|c|}{ Levene's test } & \multicolumn{2}{|c|}{$\begin{array}{l}\text { High SOP-S group } \\
\quad N=173\end{array}$} & \multicolumn{2}{|c|}{$\begin{array}{l}\text { Low SOP-S group } \\
\quad N=250\end{array}$} & \multicolumn{4}{|c|}{ Statistical sig. and magnitude of differences } \\
\hline & $F$ & $p$ & $M$ & $S D$ & $M$ & $S D$ & $t$ & $g l$ & $p$ & $d$ \\
\hline$\overline{\mathrm{PA}}$ & 1.28 & .257 & 20.41 & 4.05 & 19.02 & 3.92 & -4.92 & 421 & $<.001$ & .35 \\
\hline NA & .68 & .407 & 8.34 & 3.92 & 8.91 & 3.86 & 2.07 & 421 & .039 & .15 \\
\hline Extraversion & 4.30 & .038 & 46.68 & 9.43 & 43.10 & 9.82 & -5.57 & 358.06 & $<.001$ & .37 \\
\hline Agreeableness & 24.34 & .000 & 49.42 & 11.04 & 45.23 & 12.44 & -5.28 & 328.85 & $<.001$ & .36 \\
\hline Consciousness & 5.91 & .015 & 48.90 & 10.74 & 44.80 & 11.43 & -5.53 & 343.39 & $<.001$ & .37 \\
\hline Neuroticism & 14.77 & .000 & 33.19 & 9.81 & 36.39 & 11.32 & 4.46 & 339.80 & $<.001$ & .31 \\
\hline Openness & .61 & .435 & 47.31 & 10.15 & 43.28 & 10.28 & -5.97 & 421 & $<.001$ & .40 \\
\hline
\end{tabular}

\section{Logistic regression}

Results of logistic regressions for the predictive capability of affect and the Big Five traits of personality on high levels of SOP-C (see Table 4) revealed that NA and Neuroticism positively and significantly predicted high levels of SOP-C. However, Agreeableness, Consciousness and Openness to Experience were negative and significant predictors of SOPC.

The proportion of correctly classified cases ranged from $60.8 \%$ to $64.3 \%$ and the Nagelkerke's $R^{2}$ was between .01 and .05 . Thus, it was found that for each point of increase in levels of NA and Neuroticism, the probability of having high SOP-C increases by $12 \%$ and $4 \%$, respectively. On the other hand, the probability of having high SOP-C decreases by $2 \%$ for each point that scores in Agreeableness, Consciousness and Openness to Experience increase.

Table 5 presents the results of logistic regressions that assess the predictive capability of affect and the Big Five personality traits on high levels of SOP-S. The percentage of correctly classified cases ranged from $60.2 \%$ to $67.5 \%$, and Nagelkerke's $R^{2}$ ranged from .01 to .05 . The OR levels indicated that the probability of having high levels of SOP-S increases by $9 \%, 4 \%, 3 \%, 3 \%$ and $4 \%$ for each point that scores on PA, Extraversion, Agreeableness, Consciousness and Openness to Experience increase, respectively. To the contrary, this probability decreases by $4 \%$ and $3 \%$ for each point that the levels of NA and Neuroticism increase, respectively. 
Table 4. Binary Logistic Regression for the probability to present high SOP-C according to dimensions of 10-item PANAS-C and the BFQ-C.

\begin{tabular}{|c|c|c|c|c|c|c|c|c|c|}
\hline Variable & & $\chi^{2}$ & $\mathrm{R}^{2}$ & $\mathrm{~B}$ & E.T. & Wald & $p$ & OR & C.I. $95 \%$ \\
\hline \multirow[t]{2}{*}{$\mathrm{NA}$} & Correctly clas.: $60.8 \%$ & 27.86 & .05 & .11 & .02 & 24.34 & $<.001$ & 1.12 & $1.07-1.17$ \\
\hline & Constant & & & -.52 & .20 & 6.46 & .01 & .60 & \\
\hline \multirow[t]{2}{*}{ Agreeableness } & Correctly clas.: $61.7 \%$ & 10.78 & .02 & -.02 & .01 & 10.39 & .001 & .98 & $.97-.99$ \\
\hline & Constant & & & 1.41 & .30 & 22.03 & $<.001$ & 4.09 & \\
\hline \multirow[t]{2}{*}{ Consciousness } & Correctly clas.: $61.7 \%$ & 12.74 & .02 & -.02 & .01 & 12.23 & $<.001$ & .98 & $.96-.99$ \\
\hline & Constant & & & 1.55 & .32 & 23.79 & $<.001$ & 4.72 & \\
\hline \multirow[t]{2}{*}{ Neuroticism } & Correctly clas.: $64.3 \%$ & 25.41 & .04 & .04 & .01 & 24.09 & $<.001$ & 1.04 & $1.02-1.05$ \\
\hline & Constant & & & -.71 & .25 & 8.13 & .004 & .49 & \\
\hline \multirow[t]{2}{*}{ Openness to Experience } & Correctly clas.: $61.7 \%$ & 6.74 & .01 & -.02 & .01 & 6.61 & .01 & .98 & $.97-.99$ \\
\hline & Constant & & & 1.29 & .33 & 15.62 & $<.001$ & 3.65 & \\
\hline
\end{tabular}

Note: Correctly clas. $=$ Correctly classified.

Table 5. Binary Logistic Regression for the probability to present high SOP-S according to dimensions of 10-item PANAS-C and the BFQ-C.

\begin{tabular}{|c|c|c|c|c|c|c|c|c|c|}
\hline Variable & & $\chi^{2}$ & $\mathrm{R}^{2}$ & $\mathrm{~B}$ & E.T. & Wald & $p$ & OR & C.I. $95 \%$ \\
\hline \multirow[t]{2}{*}{$\overline{\mathrm{PA}}$} & Correctly clas.: $60.2 \%$ & 23.50 & .04 & .08 & .02 & 22.95 & $<.001$ & 1.09 & $1.05-1.13$ \\
\hline & Constant & & & -1.14 & .35 & 10.49 & .001 & .32 & \\
\hline \multirow[t]{2}{*}{ NA } & Correctly clas.: $62.2 \%$ & 4.21 & .01 & -.04 & .02 & 4.23 & .04 & .96 & $.93-. .99$ \\
\hline & Constant & & & .83 & .17 & 24.38 & $<.001$ & 2.29 & \\
\hline \multirow[t]{2}{*}{ Extraversion } & Correctly clas.: $65.7 \%$ & 30.89 & .04 & .04 & .01 & 30.01 & $<.001$ & 1.04 & $1.03-1.05$ \\
\hline & Constant & & & -1.05 & .32 & 11.01 & .001 & .35 & \\
\hline \multirow[t]{2}{*}{ Agreeableness } & Correctly clas.: $64.4 \%$ & 28.76 & .04 & .03 & .01 & 28.41 & $<.001$ & 1.03 & $1.02-1.04$ \\
\hline & Constant & & & & .27 & 7.82 & .005 & .47 & \\
\hline \multirow[t]{2}{*}{ Consciousness } & Correctly clas.: $65 \%$ & 30.48 & .04 & .03 & .01 & 29.95 & $<.001$ & 1.03 & $1.02-1.05$ \\
\hline & Constant & & & & .29 & 9.30 & .002 & .42 & \\
\hline \multirow[t]{2}{*}{ Neuroticism } & Correctly clas.: $67.5 \%$ & 21.27 & .03 & -.03 & .01 & 21.01 & $<.001$ & .97 & $.96-.98$ \\
\hline & Constant & & & & .23 & 51.34 & $<.001$ & 5.34 & \\
\hline \multirow[t]{2}{*}{ Openness to Experience } & Correctly clas.: $65 \%$ & 34.43 & .05 & .04 & .01 & 33.41 & $<.001$ & 1.04 & $1.03-1.05$ \\
\hline & Constant & & & & .30 & 12.20 & $<.001$ & .35 & \\
\hline
\end{tabular}

Note: Correctly clas. $=$ Correctly classified.

\section{Discussion}

The purpose of this study was to examine the relationship between intrapersonal perfectionism (i.e., SOP-C and SOP$\mathrm{S})$, affect and the Big Five personality traits in Spanish children.

Results indicate the existence of a positive and significant relationship between SOP-C and the dimensions considered maladaptive (i.e., NA and Neuroticism) as well as a negative relationship with those dimensions considered adaptive, with the exception of Extraversion and PA (i.e., Agreeableness, Consciousness and Openness to Experience). On the other hand, SOP-S seems to be positively associated with all of the adjustment variables considered in this study and negatively associated with NA and Neuroticism. As expected, this suggests that SOP-C presents a more maladaptive behavioral pattern than the SOP-S dimension, in accordance with previous research that found SOP-C to be a maladaptive dimension, with SOP-S being considered a positive character dimension, in terms of psychological adjustment (Harvey et al., 2017; Herman et al., 2013; McCreary et al., 2004; O'Connor et al., 2010).

Considering all of the variables of this study, SOP-C was more closely associated with NA and Neuroticism. Regarding NA, this relationship could be explained by the fact that according to Blatt, Afflitti and Quinlan (1976), individuals with high self-criticism are characterized by "intense feelings of inferiority, guilt and worthlessness and by a sense that one has failed to live up to expectations and standards" (pp. 383384). In other words, they tend to experience a general subjective discomfort. These results are also in accordance with previous studies, such as one conducted by Dunkley et al. (2006) who found that self-criticism was more closely associated with Negative Affect than any other component of perfectionism. Similarly, the link between Neuroticism and SOP-C is explained by the fact that a tendency to engage in self-criticism and self-punishment are traits that generate considerable discomfort in the subject, who can experience psychological anguish. Furthermore, this discomfort may trigger other internalizing problems such as depression, anxiety, etc. (Herman et al., 2013; McCreary et al., 2004; O'Connor et al., 2010). All of these have been considered correlations of emotional instability in child populations (e.g., Andrés, Richaud, Castañeiras, Canet-Juriz, \& RodríguezCarvajal, 2016; Vreeke \& Muris, 2012).

With respect to SOP-S and its association with both affective dimensions, it is possible that self-satisfaction and awards associated with this feature suggest an increase in positive affectivity, although not necessarily at the expense of psychological distress. Thus, the insignificant effect sizes that were obtained indicate that although differences exist in NA among students with high and low scores on SOP-S, these differences do not have theoretical or practical relevance (Sohn, 1982). That is, motivation and high strivings and per- 
severance in performance facilitate the scope of an individual's goals and purposes, resulting in higher levels of satisfaction and positive emotions. However, this does not imply reductions in the tendency to experience negative emotions.

On the other hand, regarding the Big Five personality traits, SOP-S was more closely linked to Extraversion and Openness to Experience. Considering the case of Extraversion, the relationship with SOP-S could be explained by the fact that SOP-S indicates the persistent and high efforts to achieve perfection, so these subjects be found to be more active, enthusiastic and self-confident. Furthermore, these situations could be more apparent at an early age, since the standards are achievable and their behaviors and perfectionist beliefs are reinforced by achieving the objectives proposed. Along the same line, for Openness to Experience, as previously mentioned, this trait considers elements referring to intellect or school proficiency (Carrasco et al., 2005). Thus, persistence and effort are two important aspects to ensure school success (Liem, 2015). Along these lines, students having high SOP-S profiles are likely to be more academically outstanding than students less motivated by achievement.

These results support the idea that SOP is better conceptualized into two independent dimensions (i.e., SOP-C and SOP-S). In fact, previous evidence on the relationship between SOP as a unitary construct, and NA are inconsistent. Thus, although many studies have observed a non-significant association between this dimension and NA (Downey et al., 2014; Flett et al., 2009; Frost et al., 1993; Molnar et al., 2006; Short \& Mazmanian, 2013), other works have found evidence in favor of a positive and significant relationship between both variables (Downey \& Chang, 2007; Stoeber \& Corr, 2015, 2016).

As for the relationship between SOP and PA, prior literature has mainly shown positive and significant correlations (Downey et al., 2014; Flett et al., 2009; Frost et al., 1993; Molnar et al., 2006; Nejad et al., 2011; Stoeber \& Corr, 2015, 2016), although some studies contradict these overall results (Dunkley et al., 2006; Short \& Mazmanian, 2013).

On the other hand, regarding the Big Five personality traits, prior research has generally found that SOP is significantly and positively linked to Consciousness (De Cuyper et al., 2015; Dunkley \& Kyparissis, 2008; Hill et al., 1997; Molnar, Flett et al., 2012; Molnar, Sadava et al., 2012; Nathanson et al., 2006; O'Connor \& O’Connor, 2004; Sherry et al., 2007; Sherry et al., 2010; Stoeber et al., 2009). Nevertheless, no evidence of a significant relationship with Extraversion (Cuttler \& Graf, 2007; Dunkley \& Kyparissis, 2008; Hill et al., 1997; Molnar, Sadava et al., 2012; Nathanson et al., 2006; Sherry et al., 2007), Agreeableness (Dunkley \& Kyparissis, 2008; Hill et al., 1997; Nathanson et al., 2006; Sherry et al., 2007) and Openness to Experience (Dunkley \& Kyparissis, 2008; Hill et al., 1997; Nathanson et al., 2006; Sherry et al., 2007; Stoeber et al., 2009) has been found. Moreover, in the case of Neuroticism, there is evidence of a positive and significant relationship (Brannan \& Petrie, 2008; Cuttler \& Graf, 2007; Enns et al., 2005; Miquelon et al., 2005;
Molnar, Flett et al., 2012; Molnar, Sadava et al., 2012; Sherry et al., 2010; Sherry \& Hall, 2009), as well as evidence of a non-significant link (Dunkley \& Kyparissis, 2008; Hill et al., 1997; Nathanson et al., 2006; Sherry et al., 2007; Stoeber et al., 2009).

Thus, these divergences may reflect the self-criticism and strivings facets of the intrapersonal perfectionism and its differential association with PA and NA and the Big Five traits of personality, in accordance with prior studies.

\section{Limitations and future research}

It is necessary to consider the limitations of this study. First, its transversal design makes it impossible to establish causal relationships between the studied variables. In the future, this aspect could be resolved through the use of structural equation modelling or longitudinal data. Secondly, results cannot be generalized to other samples distinct from the reference population considered in this study; Spanish children aged 8 to 11 . Therefore, it would be interesting to carry out longitudinal studies in order to investigate the temporal relationships between perfectionism, affect and personality, providing evidence of causal influences and the direction of these influences (Stoeber, 2018), as well as the developmental trajectories of SOP-C and SOP-S across different stages of the life cycle. On the other hand, because perfectionism may be influenced by cultural factors (DiBartolo \& Rendón, 2012), it would be convenient to test whether or not SOP-C and SOP-S have the same emotional consequences in other ethnic groups. Likewise, this work has the limitations of using self-report measures (FernándezMontalvo \& Echeburúa, 2006; Morales-Vives, Lorenzo-Seva, \& Vigil-Colet, 2017) which could be resolved by using a multi-source and multi-method assessment. Furthermore, since it has been suggested that perfectionism varies in how it is manifested by males and females (Slaney \& Ashby, 1996), and depending on the specific domain or context (Haase, Prapavessis, \& Owens, 2013; Stoeber \& Stoeber, 2009); therefore, it would be of great interest to examine whether or not the pattern of association between perfectionism dimensions and the examined variables varies according to gender and the context in which it is manifested (i.e., sport, studies, physical appearance, etc.).

\section{Conclusions}

Despite these limitations, this work is a novel contribution to research on perfectionism. Firstly, because it is the first study to examine the relationship between the Big Five personality traits and intrapersonal perfectionism in children. Secondly, because research on perfectionism has generally considered only English-speaking populations. Thus, this work contributes to the understanding of its emotional consequences and association with the Big Five personality traits in other cultures as the Spanish. Thirdly, because prior studies examining the correlates of SOP-C and SOP-S are limited and have 
been mainly based on measures of maladjustment (excluding the work of Harvey et al., 2017), this work helps to better understand the nature of these two dimensions, also considering the link with adaptive variables.

Finally, it is important to highlight some practical implications derived from these results. It is a proven fact that a close link exists between perfectionism and general psychopathology, not only in adult population (Egan, Wade, \& Shafran, 2011, 2012) but also during childhood and adolescence (Morris \& Lomax, 2014). Hence several authors have warned of the importance of preventing perfectionism as of early ages (Inglés, García-Fernández, Vicent, Gonzálvez, \& Sanmartín, 2016). However, the need for intervention has been hampered, in part, due to the lack of agreement as to which perfectionist facets must be addressed and which facets must be conserved or even promoted, with SOP being a clear example of this debate (e.g., Flett \& Hewitt, 2006; Lo \& Abbott, 2013; Owens \& Slade, 2008). These results, in ac-

\section{References}

Andrés, M.L., Richaud, M.C., Castañeiras, C., Canet-Juric, L., \& RodríguezCarvajal, R. (2016). Neuroticism and depression in children: the role of cognitive emotion regulation strategies. The Journal of Genetic Psychology, 177(2), 55-71. https://doi.org/10.1080/00221325.2016.1148659

Barbaranelli, C., Caprara, G., Rabasca, A., \& Pastorelli, C. (2003). A questionnaire for measuring the Big Five in late childhood. Personality and Individual Differences, 34, 645-664. https://doi.org/10.1016/S01918869(02)00051-X

Blatt, S.J., D’ Afflitti, J.P., \& Quinlan, D.M. (1976). Experiences of depression in normal young adults. Journal of Abnormal Psychology, 85, 383-389. https://doi.org/10.1037/0021-843X.85.4.383

Brannan, M.E., \& Petrie, T.A. (2008). Moderators of the body dissatisfaction-eating disorder symptomatology relationship: replication and extension. Journal of Counseling Psychology, 55(2), 263-275. https://doi.org/10.1037/0022-0167.55.2.263

Burgess, A.M., DiBartolo, M.P., \& Rendón, M.J. (2016). Can the Frost Multidimensional Perfectionism Scale assess perfeccionsimo? Psychological Assessment, 8. https://doi.org/10.1037/pas0000374

Carrasco, M.A., Holgado, F.P., \& Del Barrio, M.V. (2005). Dimensionality of the questionnaire of the Big Five traits (BFQ-N) in child population. Psicothema, 17(2), 286-291.

Cohen, J. (1988). Statistical power analysis for the behavioral sciences. Hillsdale, NJ: Erlbaum.

Cuttler, C., \& Graf, P. (2007). Personality predicts prospective memory task performance: an adult lifespan study. Scandinavian Journal of Psychopathology, 48(3), 215-231. https://doi.org/10.1111/j.1467-9450.2007.00570.x

De Cuyper, K., Claes, L., Hermans, D., Pieters, G., \& Smits, D. (2015). Psychometric properties of the multidimensional perfectionism scale of Hewitt in a Dutch-speaking sample: associations with the Big Five personality traits. Journal of Personality Assessment, 97(2), 182-190. https://doi.org/10.1080/00223891.2014.963591

De Maris, A. (2003). Logistic regression. In J.A. Schinka \& W.F. Velicer (Eds.), Research methods in psychology (pp. 509-532). Nueva Jersey: John Wiley \& Sons.

Dibartolo, P., \& Rendón, M.J. (2012). A critical examination of the construct of perfectionism and its relationship to mental health in Asian and African Americans using a cross-cultural framework. Clinical Psychology Review, 32(3), 139-152. https://doi.org/10.1016/j.cpr.2011.09.007

Downey, C.A., \& Chang, E.C. (2007). Perfectionism and symptoms of eating disturbances in female college students: considering the role of negative affect and body dissatisfaction. Eating Behaviors, 8, 497-503. https://doi.org/10.1016/j.eatbeh.2007.02.002 cordance with some previous studies, support the idea that SOP is better conceptualized using two dimensions, one having an adaptive nature (SOP-S) and the other being clearly maladaptive (SOP-C). So, this may be both a plausible explanation and a solution to this debate. Consequently, it may be convenient for works attempting to prevent perfectionism in children focus not only on interpersonal facets (e.g., Socially Prescribed Perfectionism) traditionally considered to be maladaptive (Vicent, Inglés, Sanmartín, Gonzálvez, GranadosAlós et al., 2017; García-Fernández, Vicent, Inglés, Gonzálvez, \& Sanmartín, 2017), but also on reducing levels of selfcriticism and fear of making mistakes.

Acknowledgements.- This manuscript was supported by the Ministry of Science and Innovation of Spain with the project awarded to José Manuel García-Fernández (EDU2012-35124); and the VALi+d Program (ACIF/2014/368), granted to María Vicent.

Downey, C.A., Reinking, K.R., Gibson, J.M., Cloud, J.A., \& Chang, E.C. (2014). Perfectionistic cognitions and eating disturbance: distinct mediational models for males and females. Eating Behaviors, 15, 419-426. https://doi.org/10.1016/j.eatbeh.2014.04.020

Dunkley, D.M., \& Kyparissis, A. (2008). What is DAS self-critical perfectionism really measuring? Relations with the five-factor model of personality and depressive symptoms. Personality and Individual Differences, 44(6), 1295-1305. https://doi.org/10.1016/j.paid.2007.11.022

Dunkley, D.M., Zuroff, D.C., \& Blankstein, K.R. (2006). Specific perfectionism components versus self-criticism in predicting maladjustment. Personality and Individual Differences, 40, 665-676. https://doi.org/10.1016/j.paid.2005.08.008

Ebesutani, C., Regan, J., Smith, A., Reise, S., Higa-McMillan, C., \& Chorpita, B.F. (2012). The 10-Item Positive and Negative Affect Schedule for Children, Child and Parent Shortened Versions: application of item response theory for more efficient assessment. Journal of Psychopathology and Behavioral Assessment, 34(2), 191-203. https://doi.org/10.1007/s10862-011-9273-2

Egan, S.J., Wade, T.D., \& Shafran, R. (2011). Perfectionism as a transdiagnostic process: a clinical review. Clinical Psychology Review, 31, 203-212. https://doi.org/10.1016/j.cpr.2010.04.009

Egan, S.J., Wade, T.D., \& Shafran, R. (2012). The transdiagnostic process of perfectionism. Revista de Psicopatología y Psicología Clínica, 17(3), 279294.

Enns, M.W., Cox, B.J., \& Clara, I.P. (2005). Perfectionism and neuroticism: a longitudinal study of specific vulnerability and diathesis-stress models. Cognitive Therapy and Research, 29(4), 463-478. https://doi.org/10.1007/s10608-005-2843-04

Fernández-Montalvo, J., \& Echeburúa, E. (2006). Uso y abuso de los autoinformes en la evaluación de los trastornos de personalidad. Revista de Psicopatología y Psicología Clínica, 11(1), 1-12.

Flett, G.L., \& Hewitt, P.L. (2006). Positive versus negative perfectionism in psychopathology: a comment on Slade and Owens's dual process model. Behavior Modification, 30, 472-495. https://doi.org/10.1177/0145445506288026

Flett, G.L., Blankstein, K.R., \& Hewitt, P.L. (2009). Perfectionism, performance, and state positive affect and negative affect after a classroom test. Canadian Journal of School Psychology, 24, 4-18. https://doi.org/10.1177/0829573509332457

Flett, G.L., Hewitt, P.L., Besser, A., Su, C., Vaillancourt, T., Boucher, D., Munro, Y., Davidson, L.A., \& Gale, O. (2016). The Child-Adolescent Perfectionism Scale: development, psychometric properties, and associations with stress, distress, and psychiatric symptoms. Journal of Psy- 
choeducational Assessment, 34(7),

634-652. https://doi.org/10.1177/0734282916651381

Frost, R.O., Heimberg, R.G., Holt, C.S., Mattia, J.I., \& Nuebauer, M. (1993). A comparison of two measures of perfectionism. Personality and Individual Differences, 14, 119-126. https://doi.org/10.1016/0191$8869(93) 90181-2$

García-Fernández, J.M., Inglés, C.J., Vicent, M., Gonzálvez, C., GómezNúñez, M.I., \& Poveda-Serra, P. (2016). Perfeccionismo durante la infancia y la adolescencia. Análisis bibliométrico y temático (2004-2014) Perfectionism during childhood and adolescence. Bibliometric and thematic analysis (2004-2014)]. Revista Iberoamericana de Psicologia y Salud, 7, 79-88. https://doi.org/10.1016/j.rips.2016.02.001

García-Fernández, J.M., Vicent, M., Inglés, C.J, Gonzálvez, C., \& Sanmartín, R. (2017). Relación entre el perfeccionismo socialmente prescrito y la conducta agresiva durante la infancia tardía Relationship between socially prescribed perfectionism and aggressive behavior during late childhood]. European Journal of Education and Psychology, 10, 15-22. https://doi.org/10.1016/j.ejeps.2016.10.003

Gaudreau, P., \& Verner-Filion, J. (2012). Dispositional perfectionism and well-being: a test of the $2 \times 2$ model of perfectionism in the sport domain. Sport, Exercise and Performance Psychology, 1(1) 29-43. https://doi.org/10.1037/a0025747

Haase, A.M., Prapavessis, H., \& Owens, R.G. (2013). Domain-specificity in perfectionism: variations across domains of life. Personality and Individual Differences, 55, 711-715. https://doi.org/10.1016/i.paid.2013.05.025

Hambleton R.K., \& Lee M.K. (2015). Methods for translating and adapting tests to increase cross-language validity. In D.H. Saklofske, C.R. Reynolds and V.L. Schwean (Eds.), The Oxford Handbook of Child Psychological Assessment (pp. 172-181). New York, NY: Oxford University Press.

Harvey, B.C., Moore, A.M., \& Koestner, R. (2017). Distinguishing selforiented perfectionism-striving and self-oriented perfectionism-critical in school-aged children: Divergent patterns of perceived parenting, personal affect and school performance. Personality and Individual Differences, 113, 136-141. https://doi.org/10.1016/j.paid.2017.02.069

Herman, K.C., Wang, K., Trotter, R., Reinke, W.M., \& Ialongo, N. (2013). Developmental trajectories of maladaptive perfectionism among African American adolescents. Child Development, 84(5), 1633-1650. https://doi.org/10.1111/cdev.12078

Hewitt, P.L., Flett, G.L., Besser, A., Sherry, S.B., \& McGee, B. (2003). Perfectionism is multidimensional: a reply to Shafran, Cooper \& Fairburn (2002). Behaviour Research and Therapy, 41, 1221-1236. https://doi.org/10.1016/S0005-9767(03)00021-4

Hill, R.W., McIntire, K., \& Bacharach, V.R. (1997). Perfectionism and the big five factors. Journal of Social Behavior and Personality, 12(1), 257-270.

Ho, M.S.H., Appleton, P.R., Cumming, J., \& Duda, J.L. (2015). Examination the relationship between perfectionism dimensions and burning out symptoms in deaf and hearing athletes. Journal of Clinical Sport Psychology, 9, 156-172. https://doi.org/10.1123/jcsp.2014-0035

Inglés, C.J, García-Fernández, J.M., Vicent, M., Gonzálvez, C., \& Sanmartín, R. (2017). Profiles of perfectionism and school anxiety: a review of the $2 \times 2$ model of dispositional perfectionism in child population. $\begin{array}{llll}\text { Frontiers in } & \text { Psychology, } & \text { 7(1), } & \text { 17-29. }\end{array}$ https://doi.org/10.1989/ejihpe.v7i1.192

Liem, G.A. (2015). Academic and social achievement goals: their additive, interactive, and specialized effects on school functioning. British Journal of Educational Psychology, $\quad 86(1), \quad 37-56$. https://doi.org/10.1111/bjep.12085

Lo, A., \& Abbott, M.J. (2013). Review of the theoretical, empirical, and clinical status of adaptive and maladaptive perfectionism. School of Psychology, 2(30), 96-116. https://doi.org/10.1017/bec.2013.9

McCreary, B.T., Joiner, T.E., Schmidt, N.B., \& Ialongo, N.S. (2004). The structure and correlates of perfectionism in African American children. Journal of Clinical Cbild \& Adolescent Psychology, 33, 313-324. https://doi.org/10.1207/s15374424jccp3302_13

Miquelon, P., Vallerand, R.J., Grouzet, F.M.E., \& Cardinal, G. (2005). Perfectionism, academic motivation, and psychological adjustment: an integrative model. Personality and Social Psychology Bulletin, 31(7), 913-924. https://doi.org/10.1177/0146167204272298
Molnar, D.S., Flett, G.L., Sadava, S.W., \& Colautti, J. (2012). Perfectionism and health functioning in women with fibromyalgia. Journal of Psychosomatic Research, 73(4), https://doi.org/10.1016/j.jpsychores.2012.08.001

295-300.

Molnar, D.S., Reker, D.L., Culp, N.A., Sadava, S.W., \& DeCourville, N.H. (2006). A mediated model of perfectionism, affect, and physical health. Journal of Research in Personality, 40, 482-500. https://doi.org/10.1016/j.jrp.2005.04.002

Molnar, D.S., Sadava, S.W., Flett, G.L., \& Colautti, J. (2012). Perfectionism and health: a mediational analysis of the roles of stress, social support and health-related behaviours. Psychology and Health, 27(7), 846-864. https://doi.org/10.1080/08870446.2011.630466

Morales-Vives, F., Lorenzo-Seva, U., \& Vigil-Colet, A. (2017). How response biases affect the factor structure of Big Five personality questionnaires. Anales de psicologia, 33 (3), 589-596. http://dx.doi.org/10.6018/analesps.33.2.254841

Morris, L., \& Lomax, C. (2014). Review: assessment, development, and treatment of childhood perfectionism: a systematic review. Child and Adolescent Mental Health, 19(4), 225-234. https://doi.org/10.1111/camh.12067

Nathanson, C., Paulhus, D.L., \& Williams, K.M. (2006). Predictors of a behavioral measure of scholastic cheating: personality and competence but not demographics. Contemporary Educational Psychology, 31, 97-122. https://doi.org/10.1016/j.cedpsych.2005.03.001

Nejad, E.M., Ali-Besharat, M., Haddadi, P., \& Abdolmanafi, A. (2011). Mediation effects of positive and negative affect on the relationship between perfectionism and physical health. Procedia - Social and Behavioral Sciences, 30, 176-181. https://doi.org/10.1016/j.sbspro.2011.10.035

O'Connor, D.B., \& O'Connor, R.C. (2004). Perceived changes in food intake in response to stress: the role of conscientiousness. Stress and Health, 20(5), 279-291. https://doi.org/10.1002/smi.1028

O'Connor, R.C., Dixon, D., \& Rasmussen, S. (2009). The structure and temporal stability of the Child and Adolescent Perfectionism Scale. Psychological Assessment, 21(3), 437-443. https://doi.org/10.1037/a0016264

O'Connor, R.C., Rasmussen, S., \& Hawton, K. (2010). Predicting depression, anxiety and self-harm in adolescents: the role of perfectionism and acute life stress. Behaviour Research and Therapy, 48, 52-59. https://doi.org/10.1016/i.brat.2009.09.008

Oros, L.B. (2005). Implications of child perfectionism on psychological welfare: Guidelines for diagnosis and clinical practice. Anales de Psicologia, 21(2), 294-303

Owens, R.G., \& Slade, P.D. (2008). So perfect it's positively harmful? Reflections on the adaptiveness and maladaptiveness of positive and negative perfectionism. Behavior Modification, 43, 472-495. https://doi.org/10.1177/0145445508319667

Sherry, S.B., \& Hall, P.A. (2009). The perfectionism model of being eating: tests of an integrative model. Journal of Personality and Social Psychology, 96(3), 690-709. https://doi.org/10.1037/a0014528

Sherry, S.B., Hewitt, P.L., Flett, G.L., Lee-Baggley, D.L., \& Hall, P.A. (2007). Trait perfectionism and perfectionistic self-presentation in personality pathology. Personality and Individual Differences, 42, 477-490. https://doi.org/10.1016/j.paid.2006.07.026

Sherry, S.B., Hewitt, P.L., Sherry, D.L., Flett, G.L., \& Graham, A.R. (2010). Perfectionism dimensions and research productivity in psychology professors: implications for understanding the (mal) adaptiveness of perfectionism. Canadian Journal of Behavioural Sciences, 42(4), 273-283. https://doi.org/10.1037/a0020466

Short, M.M., \& Mazmanian, D. (2013). Perfectionism and negative repetitive thoughts: examining a multiple mediator model in relation to mindfulness. Personality ad Individual Differences, 55, 716-721. https://doi.org/10.1016/i.paid.2013.05.026

Slaney, R.B., \& Ashby, J.S. (1996). Perfectionists: study of a criterion Group. Journal of Counseling and Development, 74(4), 393-398. https://doi.org/10.1002/j.1556-6676.1996.tb01885.x

Sohn, D. (1982). Sex differences in achievement self-attributions: An effectsize analysis. Sex Roles, 8, 345-357.

Stoeber, J. (2017). The psychology of perfectionism: critical issues, open questions, and future directions. In J. Stoeber (Ed.), The psychology of perfectionism: theory, research, applications (pp. 333-352). London: Routledge. 
Stoeber, J., \& Corr, P.J. (2015). Perfectionism, personality, and affective experiences: new insights from revised reinforcement sensitivity theory. Personality and Individual Differences, 86, 354-359. https://doi.org/10.1016/j.paid.2015.06.045

Stoeber, J., \& Corr, P.J. (2016). A short empirical note on perfectionism and flourishing. Personality and Individual Differences, 90, 50-53. https://doi.org/10.1016/j.paid.2015.10.036.

Stoeber, J., \& Stoeber, F.S. (2009). Domains of perfectionism: prevalence and relationships with perfectionism, gender, age, and satisfaction with life. Personality and Individual Differences, 26, 530-535. https://doi.org/10.1016/j.paid.2008.12.006

Stoeber, J., Otto, K., \& Dalbert, C. (2009). Perfectionism and the Big Five: conscientiousness predicts longitudinal increases in self-oriented perfectionism. Personality and Individual Differences, 47, 363-368. https://doi.org/10.1016/j.paid.2009.04.004

Vicent, M. (2017). Estudio del perfeccionismo y su relación con variables psicoeducativas en la infancia tardia S Study of perfectionism and its relationship with psychoeducational variables during late childhood] (Doctoral thesis). University of Alicante, Spain.
Vicent, M., Inglés, C.J, Sanmartín, R., Gonzálvez, C., \& García-Fernández, J.M. (2017). Perfectionism and aggression: identifying risk profiles in children. Personality and Individual Differences, 112, 106-112. https://doi.org/10.1016/j.paid.2017.02.061

Vicent, M., Inglés, C.J, Sanmartín, R., Gonzálvez, C., Granados-Alós, L., \& García-Fernández, J.M. (2017). Perfeccionismo socialmente prescrito y afectividad en población infantil española [Socially prescribed perfectionism and affectivity in Spanish child population]. European Journal of Investigation in Health, Psychology and Education, 7(1), 17-29. https://doi.org/10.1989/ejihpe.v7i1.192

Vreeke, L.J., \& Muris, P. (2012). Relations between behavioral inhibition, big five personality factors, and anxiety disorder symptoms in nonclinical and clinically anxious children. Child Psychiatry \& Human Development, 43, 884-894. https://doi.org/10.1007/s10578-012-0302-5

Walton, G.L., Hibbard, D.R., Coughlin, C., \& Coyl-Shepherd, D.D. (2018). Parenting, personality, and culture as predictors of perfectionism. Current Psychology. https://doi.org/10.1007/s12144-018-9793-y 